\title{
LA IDENTIDAD DEL ADOLESCENTE Y SU RELACIÓN CON EL IMAGINARIO NACIONAL COSTARRICENSE \\ THE ADOLESCENT IDENTITY AND ITS RELATIONSHIP WITH THE NATIONAL IMAGINARY
}

\author{
Volumen 14, Número 2 \\ Mayo - Agosto \\ pp. 1-32
}

Este número se publicó el 30 de mayo de 2014

\author{
Lucía Arroyo Chinchilla \\ Paula Huertas Castro \\ Claudia Peirano Cisterna \\ Maureen Pérez Calvo
}

Revista indizada en REDALYC,

Revista distribuida en las bases de datos:

CATÁLOGO DE LATINDEX, IRESIE, CLASE, DIALNET, DOAJ, E-REVIST@S, SHERPA/ROMEO, QUALIS, MIAR

Revista registrada en los directorios:

ULRICH'S, REDIE, RINACE, OEI, MAESTROTECA, PREAL, CLASCO 


\title{
LA IDENTIDAD DEL ADOLESCENTE Y SU RELACIÓN CON EL IMAGINARIO NACIONAL COSTARRICENSE THE ADOLESCENT IDENTITY AND ITS RELATIONSHIP WITH THE NATIONAL IMAGINARY
}

\author{
Lucía Arroyo Chinchilla ${ }^{1}$ \\ Paula Huertas Castro ${ }^{2}$ \\ Claudia Peirano Cisterna ${ }^{3}$ \\ Maureen Pérez Calvo ${ }^{4}$
}

\begin{abstract}
Resumen: En este artículo se analiza cómo la persona adolescente se identifica con lo que conoce como las características fundamentales del ser costarricense, con el fin de determinar si ha habido algún cambio generacional en la construcción del imaginario nacional. Para obtener estos datos, se trabajó con un grupo focal, compuesto por 13 hombres y 4 mujeres, con edades entre 14 y 18 años, del Centro Internacional de Avivamiento, en San Diego de Tres Ríos. La información se sistematizó y analizó cualitativamente mediante categorías. Se demostró que los adolescentes no están exentos del contacto con la "cultura nacional", pero consideran necesario redefinir los símbolos patrios, puesto que no representan la multiculturalidad que evidencia la realidad del país.
\end{abstract}

Palabras clave: ADOLESCENCIA, IMAGINARIO NACIONAL, IDENTIDAD, COSTA RICA.

\begin{abstract}
This article analyzes how the adolescents identified themselves with what is known as the fundamental characteristics about the Costa Rican being, aiming to discover if there are any generational changes in the construction of the national imaginary. To obtain the data, work was done with a focus group of 13 men and 4 women aged between 14 and 18, who regularly attend the International Revival Center in San Diego de Tres Rios. The information was systematized and analyzed qualitatively by analytical categories. This article shows that adolescents are not exempted from contact with the "national culture", but considered necessary to redefine the symbols, because they do not represent the multicultural reality of the country.
\end{abstract}

Key words: ADOLESCENCE, NATIONAL IMAGINARY, IDENTITY, COSTA RICA.

\footnotetext{
${ }^{1}$ Estudiante de Bachillerato en Enseñanza del Castellano y Literatura de la Universidad de Costa Rica (UCR). Bach. en Filología Española de la UCR. Asistente en el Semanario Universidad de la UCR. Dirección electrónica: felespelosusest@gmail.com

${ }^{2}$ Estudiante de Bach. en Enseñanza del Castellano y Literatura de la Universidad de Costa Rica (UCR). Bach. Filología Española de la UCR. Asistente en el Centro de Evaluación Académica de la UCR. Dirección electrónica: paulahuertas2323@gmail.com

${ }^{3}$ Estudiante de Bach. en Enseñanza del Castellano y Literatura de la Universidad de Costa Rica (UCR). Estudiante de la Lic. en Filología Española en la UCR. Asistente en el Programa de Posgrado en Filosofía de la UCR. Dirección electrónica: maite8687@gmail.com

${ }^{4}$ Estudiante de Bach. en la Enseñanza de la Filosofía en la Universidad de Costa Rica (UCR). Asistente en la Biblioteca Luis Dimetrio Tinoco como encargada del laboratorio de cómputo $y$ en la Facultad de Educación de la UCR. Dirección electrónica: mahuka8390@gmail.com
}

Artículo recibido: 13 de setiembre, 2013

Devuelto para corrección: 8 de noviembre, 2013

Aprobado: 3 de marzo, 2014 


\section{Introducción}

Al hablar de un país se suele pensar en un territorio delimitado, un Gobierno autosuficiente y una población con tradiciones folklóricas "específicas" con respecto a otros Estados-naciones. Esta separación surge de la construcción discursiva, e intencional, de un imaginario nacional, que organiza y unifica la población dispersa en una cultura hegemónica.

Costa Rica, como estado nación independiente, posee desde el siglo XIX su propio conglomerado de discursos que utiliza para configurar políticamente a la población en torno a una identidad, tema que ha sido ampliamente analizado por diferentes disciplinas, como las ciencias sociales, la filosofía, la literatura, el arte, etc. Empero, este tema no ha sido abordado desde la perspectiva de las personas adolescentes, a pesar de que no solo están determinadas por sus pares, familia, gente adulta en contacto y la escuela, sino por la historia, cultura, ideologías, actitudes, costumbres, políticas de salud pública, sexual, de empleo, de educación y económicas de una sociedad.

Lo anterior obedece a que los adolescentes a menudo no son considerados en la toma de decisiones; sin embargo, en temas como la construcción de un proyecto país o las características que "nos definen como costarricenses", los jóvenes tienen un papel clave, pues ellos darán la continuidad o se distanciarán de dichas características. Al respecto, Castrillo (1998) señala que, en el proceso de la adolescencia, "el joven toma conciencia de la relatividad de las concepciones ideológicas e intenta, según sus posibilidades e intereses, discutirlas y justificarlas, adoptando frente a ellas una posición personal que le sitúa en relación con los demás y que le diferencia" (Castrillo, 1998, p.22).

Así, tal y como lo menciona Krauskopf (1998), el adolescente es un actor estratégico del desarrollo, con capacidades y derechos para intervenir protagónicamente en su presente, cambiar los estereotipos y aportar al desarrollo colectivo, razón por la cual procede conocer su posición sobre la percepción del imaginario nacional y su relación durante la construcción de su propia identidad.

De manera que, este estudio tomó en cuenta el diálogo que se establece entre adolescentes y la construcción identitaria nacional costarricense. Con base en teorías de la sociocrítica, que investigan la relación de la literatura con la sociedad y se encargan de la construcción de conceptos tales como cultura, sujeto cultural, nación, entre otras, se expondrán, inicialmente, las características asignadas, a lo largo de la historia, a ese "ser costarricense". Posteriormente, se expondrá cómo se llevó a cabo un grupo focal para 
conocer la situación actual de dichos adolescentes frente al imaginario nacional, y se analizará cómo afecta la cultura en su propia identidad.

El interés de analizar la situación actual de la identidad del "ser costarricense" y del imaginario nacional, a partir de la visión que tienen los adolescentes al respecto, surge debido a los cambios que se evidencian en dicha cultura en relación con el constructo de identidad nacional, según la ideología dominante que vive cada generación, y cuya herencia social atraviesa a los ciudadanos, máxime a los jóvenes quienes crecen con las nuevas propuestas.

De modo que el objetivo general de la investigación fue analizar la identificación del adolescente actual, durante el proceso de formación de su identidad, con las características fundamentales del ser costarricense, con la finalidad de visibilizar un posible cambio generacional, en cuanto a la construcción del imaginario nacional.

Los objetivos específicos fueron: determinar las características del ser costarricense según el imaginario nacional desde la perspectiva del adolescente actual, así como analizar la identificación de ese adolescente con el ser costarricense del imaginario nacional, para explorar las características del ser costarricense que el adolescente toma en cuenta en el proceso de construcción de su identidad.

A continuación, se expondrán los resultados.

\section{Referente teórico}

\subsection{Definición de adolescente y la construcción de su identidad}

La adolescencia es una etapa del desarrollo del ser humano cuya conceptualización presenta una gran complejidad, debido a las transformaciones que se experimentan. Al dar cuenta de las implicaciones de la noción de este estadio del desarrollo, así como la importancia de conocer o entender el proceso de construcción de la identidad, es preciso referirse a los teóricos que han sido más significativos para realizar esta tarea: Piaget, desde los postulados del desarrollo cognitivo; Erikson, a partir de la propuesta de las etapas psicosociales; Grosser, y Krauskopf, por su amplio trabajo en el campo de adolescencia propiamente en Costa Rica, entre otros que se mencionan de seguido.

Para iniciar con la definición de la adolescencia, los teóricos D'Antoni y Pacheco aseveran que dicha etapa es 
[...] una construcción sociohistórica que trasciende la mera condición etaria [...] su definición puede variar según las necesidades, la estructura económica, social y política, las atribuciones al papel sexual, la organización del tiempo, la duración promedio y las condiciones de vida de los grupos humanos particulares (2004, p. 28).

Durante este periodo, la persona adolescente comienza a experimentar una serie de cambios físicos, emocionales, conductuales, intelectuales y sociales, los cuales son necesarios para que pueda consolidar su identidad y definir el ser humano que será. Rice (1994) retoma la visión psicosocial sobre la adolescencia de Erik Erikson, quien propuso que existen 8 etapas del desarrollo humano y en cada una el individuo debe superar una tarea psicosocial que permitirá el desarrollo saludable de la identidad. Adquirir una identidad individual positiva es un proceso que dura toda la vida, y la tarea psicosocial por excelencia durante la adolescencia, de acuerdo con Erikson, es la formación de la identidad.

En consonancia con Erikson, Cubero señala que una de las principales tareas del adolescente es consolidar una identidad propia. La teórica afirma que esta es la principal tarea en la adolescencia: "el adolescente debe estructurar un conjunto de información sobre él mismo, integrarla y consolidar una respuesta que le permita identificarse como él mismo y diferenciarse de los demás" (1995, p. 5).

Es necesario para la persona adolescente, especialmente durante el proceso de construcción de su identidad, desligarse de los vínculos que la mantienen cerca del padre y la madre. La persona, en esta etapa, requiere experimentar por sí misma, probar diferentes roles y relacionarse con otros individuos, principalmente con otras personas de su edad; de ahí que en la adolescencia se establece un fuerte apego con el grupo de pares.

En relación con lo anterior, Grosser (2003), retomando a Rodulfo (1996), hace referencia al pasaje de lo familiar a lo extrafamiliar, y lo describe como "una 'metamorfosis', una transformación [...] por primera vez lo extrafamiliar deviene más importante que lo familiar" (2004, p. 11). Para la persona adolescente, su grupo de pares es muy significativo, considera que son los únicos que lo comprenden y que comparten puntos de vista muy parecidos; los padres, por el contrario, pasan a ser considerados anticuados. La vinculación con el grupo de pares resulta fundamental para el proceso de consolidación de la identidad del adolescente. 
Cabe mencionar que esta investigación tomó en cuenta el aporte de Piaget en relación con la transición del desarrollo cognitivo en la adolescencia, a partir de una adolescencia media (entre los 14 y 16 años), en la cual el individuo empieza a crear un código ético y a desarrollar su propia identidad, así como la adolescencia tardía (entre 17 y 19 años), en la que el individuo piensa acerca de conceptos más globales, como la justicia, la historia, la política y el patriotismo, y desarrolla puntos de vista idealistas acerca de temas o cuestiones específicas.

\subsection{Investigaciones sobre el desarrollo de la identidad en los adolescentes}

En cuanto al tema abordado por este estudio, no se encontraron artículos o investigaciones que trataran, específicamente, la identificación del adolescente actual con el ser costarricense del imaginario nacional, durante el proceso de formación de su propia identidad. Si bien abundan los textos académicos sobre el imaginario nacional costarricense, en este apartado solo se contempló la relación de la educación con este constructo discursivo y con el adolescente.

Al respecto, Arias (2009) sostiene que la escuela es el sitio donde se construyen y reconstruyen los contenidos culturales y las relaciones sociales, lo cual coincide con Safa (1991), quien manifiesta que la educación es un proceso de socialización, entendido como "La transmisión de una herencia cultural, como un mecanismo eficaz para la resolución de conflictos sociales" (Safa, 1991, p. 24).

Badilla, Guimarães y Vargas (1995) establecen que los planes de estudio del país abordan la cultura nacional o a la identidad nacional, pero en muchas ocasiones las personas interiorizan con esto una falsa idea de homogeneidad, que oculta las diferencias regionales, étnicas, etc., las cuales existen en el territorio costarricense. Asimismo, explican que la cultura nacional está conformada por conjuntos de prácticas culturales de varios grupos, diferenciados por las características étnicas (comunidades indígenas, negros, asiáticos, mestizos de ascendencia europea) y la ubicación geográfica de dichos grupos (campo, ciudad, montaña, costa norte-valle central-sur).

Badilla et al. (1995) mencionan que el sistema educativo nacional, por un lado, proporciona poco o ningún espacio a la cultura que se vive día a día en las comunidades y los pueblos; por otro, la educación sí se compromete totalmente con la transmisión de lo que se entiende por cultura erudita u oficial, la cual está presente en los actos cívicos, libros de 
texto, o en la celebración de efemérides patrias -muchas veces consideradas por los alumnos como aburridas, según comentarios extraídos del taller-. Por ello, plantean que es importante darle un giro a los mecanismos tradicionales de transmisión de conocimiento, que tome en cuenta que existe otra interpretación u otra visión de la historia realizada por hombres y mujeres que han sido testigos o herederos de esa vivencia.

En ese sentido, Arias (2009) resalta que si bien el sistema educativo costarricense se ha encargado de reproducir ciertas normas, ritos y valores de carácter nacionalista, la educación deber ser también lo más dinámica y flexible posible, para aceptar la realidad en que se está viviendo. El autor explica que el aula constituye uno de los lugares más apropiados para reconocer la forma en que el estudiantado, como seres pertenecientes a una comunidad, se identifica con ella o no, pues ahí, junto con los educadores, comparten conocimientos, valores, etc., que forman parte de su identidad.

En cuanto a lo anterior, Escobar (1995) menciona que la adolescencia es vista como un fenómeno social que ha adquirido gran relevancia, por lo que recalca los procesos sociales utilizados para la convivencia de una sociedad, y los define como "el proceso educativo, formal e informal, que persigue suministrar al nuevo miembro la formación y la formación necesaria para que conforme su conducta a los valores, creencias y normas vigentes" (Escobar, 1995, p. 25).

Finalmente, el autor resalta el dinamismo de la sociedad en cuanto a las generaciones, pues se presenta cómo desde una visión adulta, se transmite a la juventud la cultura que ha hecho, la cual ha sido transmitida por una generación anterior -es decir, la cultura heredada- y del resultado de su experiencia y la propia visión del mundo, la generación joven se apropia de esa herencia cultural y la rehace desde sus nuevas experiencia y visión.

\subsection{Cultura e identidad nacional}

La cultura es un concepto ampliamente utilizado en distintos contextos, por lo que abarca un espectro de connotaciones. Wallerstein (2004) señala que el concepto puede ser visto desde dos perspectivas; de acuerdo con el modelo básico, existen las características universales de la especie, el conjunto de rasgos que la definen como miembro de una serie de grupos (una cultura específica), y las características idiosincrásicas de cada persona (comportamientos, valores o creencias). 
De este modelo surge la definición de cultura "en primer uso", la cual hace referencia a características que no son universales ni individuales, pero que pertenecen a un "grupo específico"; y cada individuo tiene su "cultura específica", aunque forma parte de muchos grupos o de pequeñas culturas diferentes (género, sexo, raza, lengua, clase o nacionalidad). Esta definición remite a Estado-nación, tribus o grupos éticos, que tienen conciencia de grupo; además, suele distinguir la cultura de "intelectuales urbanos" o de "pobres urbanos".

La cultura "en segundo uso" se utiliza para referirse a la existencia de ciertas características dentro de cierto grupo, que se oponen a otras existentes en el seno de este. Parten, principalmente, de la oposición entre las "bellas artes" y las prácticas populares o cotidianas. Esta visión se basa en la distinción filosófica de lo ideal (mente) y lo real (cuerpo), en la cual ciertos valores, conductas u objetos, se consideran superiores con respecto a otros "reales", y está ligada a grupos dominantes como forma ideológica de control, pues "[...] es sospechosa de servir como cobertura ideológica para justificar los intereses de algunas personas (obviamente, los estratos superiores), dentro de cualquier 'grupo' o 'sistema social' determinado, frente a los de otras personas del mismo grupo" (Wallerstein, 2004, p. 252).

Circunscrito en la definición de cultura en primer uso, Jiménez (2008), en El imposible país de los filósofos, define las nociones de Estado y de nación. Señala el vínculo histórico que ha existido entre estos conceptos y define nación como: "[...] comunidad sostenida por creencias e imaginaciones. No está basada como las comunidades monásticas, los clanes o las tribus, en relaciones directas o en lazos de parentesco." (Jiménez, 2008, p. 114), que necesita de los elementos míticos de transmisión oral para existir.

Asimismo, Jiménez asegura, siguiendo a Jürgen Habermas, que en la definición moderna de Estado se incluye, no solo un poder soberano y un territorio claramente definido, sino también al "pueblo propio de un Estado (Staatsvolk)" (Jiménez, 2008, p. 95). Esta definición lo ha llevado a pensar que Estado y nación están en esencia unidos, pero no es así.

Jiménez afirma que la idea de nación "lograba crear lazos de solidaridad entre personas que, hasta entonces, eran extrañas o desconocidas entre sí. Sin esa conciencia nacional, la aparición de una base democrática para legitimar la dominación política habría sido improbable" (Jiménez, 2008, pp. 96-97). La concepción de nación como "espíritu de un pueblo" ofrece las condiciones culturales para la organización jurídica unitaria del Estado. 
Intelectuales, escritores, historiadores, filósofos, juristas, diplomáticos y militares, son quienes crean las condiciones para inventar la nación, desencadenar sentimientos de lealtad, homogeneidad y solidaridad entre las personas - quienes pasan a considerarse a sí mismas ciudadanas, pese a no contar con derechos fundamentales- y, de este modo, reforzar culturalmente las políticas estatales.

Lo anterior puede complementarse con la definición de cultura de Cros (2003), expuesta en el texto Sujeto cultural. Sociocrítica y psicoanálisis. Para Cros, la cultura es un espacio ideológico-simbólico, cuya función consiste en enraizar una colectividad en la conciencia de su propia identidad (memoria colectiva). Solo existe en la medida en que se comparte colectivamente y se diferencia de otras. La cultura se manifiesta en aspectos ideológicos y se puede exteriorizar de forma concreta por medio del lenguaje y diversas prácticas discursivas; además, se contiene y reproduce a través de un conjunto de instituciones y prácticas sociales.

Según Cros, la identificación cultural de una colectividad se lleva a cabo mediante el sujeto cultural. Este manifiesta una instancia del discurso ocupada por el Yo, donde emerge y funciona una subjetividad (proceso de identificación); está inmerso en la cultura y es el avatar del sujeto ideológico; es decir, es una "instancia que integra a todos los individuos de una colectividad" (Cros, 2003, p. 12), demuestra sumisión ideológica (reproduce reglas y estereotipos) y no remite a diferencias de clase social o género, por ejemplo.

Cros expone que toda alienación del sujeto cultural se manifiesta por medio del lenguaje, y que el discurso es heredado y para heredar, mientras que la interdiscursividad es el conjunto de prácticas discursivas que se adquieren a lo largo de la vida, al relacionarse los sujetos unos con otros, constantemente. Sumado a esto, señala el autor, los discursos se interiorizan de manera distinta en cada sujeto, porque los mecanismos de interiorización funcionan como espejo: "Digo yo porque me hablan de tú", así la subjetividad que se le presenta al otro es ilusoria, oculta los procesos de sumisión; por lo tanto, no se dice lo que se quiere, sino lo que la cultura permite.

A partir de esto, el autor retoma la idea de Lacan, de que el sujeto está partido y se debate entre el querer y el deber. En el inconsciente está todo lo que el sujeto no puede sacar a la luz, y en este se formulan cosas que no se manejan a nivel consciente, estructurado, como el lenguaje, perteneciendo a la cultura todo lo que se articula. 
Asimismo, Cros plantea una partición entre la realidad y la representación, en cuanto a la alienación que existe. La realidad aliena porque los significados que se asocian a la palabra están cargados de ideologías y el sujeto cultural se expresa por medio del enunciado, en el que se encuentra latente el sujeto del deseo. El sujeto cultural es una especie de mediador entre "yo" y "otros" que permite la convivencia, es el más reprimido, pues se limita a la aceptación social, creándose un "sujeto ideal" que vive como la sociedad espera que viva.

De manera que, en contraposición al sujeto cultural, surge el sujeto (el individuo) que se apropia, en mayor o menor grado, de su cultura, al continuar o no modelos de comportamiento, pero no puede ejercer sobre ella ninguna acción, más bien debe sumergirse en esa colectividad, para no ser castigado por la sociedad, la cual doblega y margina.

\subsection{El imaginario nacional costarricense}

Quesada (2002) define la nación como "una comunidad imaginada más que una realidad sustantiva" (p. 17). De ahí que sea fundamental comprender el papel que desempeña lo imaginario en la invención de una nación, en el imaginario específico de un país. Jiménez asegura que:

Lo imaginario está siempre presente en la historia social como condición de posibilidad del simbolismo y la funcionalidad de los sistemas sociales. Al unirse con lo simbólico, el imaginario reúne y cohesiona; al unirse con lo económico y funcional, permite sobrevivir. Lo imaginario, así entendido, no es sólo una estrategia ideológica de ocultamiento de la realidad. Es una condición de posibilidad de las representaciones que las sociedades construyen para entenderse o transformarse a sí mismas (2008, p. 154).

La noción de imaginario es compleja y, a grandes rasgos, designa un conjunto de imágenes y significaciones que permiten la representación unitaria de una sociedad, con lo cual se evita su disolución a pesar de su posible desorden. Pese a que el imaginario se inserta en un sistema de dominación, también puede estar al servicio de la negación, la oposición y la resistencia de las significaciones instituidas. 
Además de todos los conceptos ya definidos, resulta pertinente referirse a los periodos que ha atravesado el proceso de invención de la nación y de la nacionalidad costarricense. De acuerdo con Jiménez (2008), el primer momento de tal desarrollo histórico se extiende de 1821 a 1870, y es el de la formación del Estado costarricense. En este, "aparece ya esbozada una idea de su carácter excepcional [el de Costa Rica] con respecto a Centroamérica" (Jiménez, 2008, p. 85).

Entre 1870 y 1914, se presenta el segundo periodo, durante el cual la oligarquía cafetalera de tendencia liberal elabora un discurso identitario, que se construye un imaginario de nación y de nacionalidad, lejano a la realidad y al contexto costarricenses. La razón que explica el interés de los liberales por hilvanar este discurso, es el deseo de consolidar su creciente poder político en el país.

Según Quesada (2002), los liberales idearon una serie de estrategias, tanto a nivel político como social y cultural, con el fin de lograr que los habitantes del país interiorizaran como suyos los intereses oligárquicos, para "compensar imaginariamente la experiencia de subordinación económica, padecida por campesinos y obreros, y para perpetuar así la jerarquía económica y la exclusión política" (Jiménez, 2008, p. 198).

Entre las estrategias más significativas que llevan a cabo los liberales para implantar en los costarricenses su constructo ideológico de "nación" e "identidad nacional", se encuentran: la creación de un "héroe" (Juan Santamaría), de una literatura, símbolos, tradiciones e historia nacional, así como monumentos e instituciones construidos en la década de 1880 (el Archivo y la Biblioteca Nacional, el Monumento Nacional, el Teatro Nacional y el Museo Nacional) (Jiménez, 2008).

Una de las principales premisas del discurso oficial ideado por los liberales, es el imaginario de un país racialmente homogéneo, de personas blancas, prácticamente europeas. Este proceso implica la exclusión y silenciamiento de los habitantes que no calzaran dentro del estereotipo; así las cosas, la presencia de las culturas indígenas y afrocaribeñas es obviada y ocultada (Jiménez, 2008).

Según el discurso identitario elaborado por los liberales, la parte indígena en el mestizaje es pasiva, receptiva y, por lo tanto, insignificante, en términos de sangre y cultura, al provenir de la mujer aborigen; en contraposición, la parte activa y dominante del proceso de mestizaje proviene del varón blanco español. Todas estas estrategias discursivas logran situar las culturas indígenas en el pasado y constituirlas como ajenas a los costarricenses. 
Siguiendo a Jiménez, la consecuencia de esta manipulación del mestizaje es que afirma "la conservación de supuestas virtudes españolas —entre ellas el individualismo, la democracia, la sencillez y laboriosidad - a causa de la conservación de la sangre blanca" (Jiménez, 2008, p. 181).

Uno de los motivos que mueve a los liberales a buscar esta filiación ficticia con lo blanco y lo europeo, es la necesidad de establecer relaciones comerciales con el Viejo Continente, así como tratar de introducir a Costa Rica en el mercado capitalista mundial. El proyecto político de blanqueamiento de la población permitió que la significativa diferencia de clases surgida con la economía basada en el café, pasara inadvertida para el imaginario popular.

De este modo, "la narrativa nacionalista borra la herencia étnica africana y las distinciones e identidades étnicas de carácter oficial. No se habla más de los mulatos, los pardos, los esclavos negros, o los diversos grupos indígenas" (Jiménez, 2008, p. 191). Estos procedimientos truculentos refuerzan el espejismo de Costa Rica como una extensión de Europa en América (la Suiza centroamericana).

A partir de todas estas medidas, instituciones y artefactos del Estado, los liberales logran establecer una identidad nacional, un "ser costarricense" fundamentado en presunciones tales como: "La homogeneidad racial, la democracia rural de pequeños propietarios, la pureza de los sufragios, la ausencia de conflictos y violencias [...] la distribución equitativa de la tierra, la existencia de más maestros que soldados" (Jiménez, pp. 86-89). Igualmente, el discurso oficial construye al ciudadano como un "labriego sencillo, pacífico, honrado y trabajador, ligado a su Patria como a la Madre-Tierra" (Quesada, 2002, p.199), noción reforzada con el himno.

De acuerdo con Alexander Jiménez (2008), durante el tercer periodo del proceso de invención de la nación y la nacionalidad costarricenses, entre 1914 y 1948, se produce la crisis de la idea nacional liberal. Aparecen discursos alternativos acerca de la identidad nacional, elaborados tanto por intelectuales críticos del orden liberal como por artesanos con ideas de corte anarquista, socialista y comunista. Según Jiménez:

Las señas de identidad dominantes son las de un país democrático sostenido por los pequeños productores de café; se idealiza la época colonial; se atribuye a las clases oligárquicas la destrucción de la democracia rural de origen colonial. El Valle Central adquiere fuerza imaginaria como cuna de la nación y como ideal del modo de ser 
nacional [...] La nación ha llegado a ser el horizonte y envase de prácticas y discursos de los más diversos actores, aunque aún no se han integrado las regiones periféricas del Caribe y Guanacaste (2008, p. 87).

El cuarto periodo corresponde con la consolidación de Costa Rica como una nación democrática y moderna. Jiménez señala que, entre 1948 y 1980, el país deja de coincidir con el Valle Central y se produce una nacionalización de los espacios periféricos, lo que explicaría por qué el "ser costarricense" se encuentra estrechamente relacionado con el folclor guanacasteco. Se acrecienta "la sensación de ser una sociedad excepcional y superior en el ámbito de las otras sociedades centroamericanas; esta supuesta superioridad se convierte en una especie de mentalidad desde la cual son leídos todos los actos de la vida del país" (Jiménez, 2008, p. 88).

Durante esta época, se desarrolla una intelectualidad oficial costarricense, compuesta en buena parte por filósofos, que se encarga de: "[...] tramar un relato en el cual se reúnen metáforas, imágenes e imaginarios presentes desde la Independencia" (Jiménez, 2008, p. 88). A su vez, otros componentes de la identidad costarricense como el Valle, la Colonia y el campesino, son tomados en cuenta a partir de lo que aporten a la consolidación de la identidad nacional: "[...] ellos importan en la medida en que son los puntos de despliegue de la blancura étnica constitutiva de la nación" (Jiménez, 2008, p. 88).

Finalmente, Jiménez propone que, a partir de las dos décadas finales del siglo XX, se empezó a delinear un nuevo momento o periodo del proceso, del cual "sólo poseemos algunas intuiciones inconexas" (Jiménez, 2008, p. 89). El teórico señala que este quinto momento, el cual se extendería hasta la actualidad y durante el cual nacen y crecen los adolescentes actuales, debe pensarse tomando en cuenta la irrupción de los medios de comunicación, los problemas de integración regional, la inmigración nicaragüense, los problemas de integración social de la población más pobre y más joven, así como el desgaste de la credibilidad del sistema político.

\subsection{Los símbolos patrios en el entorno costarricense}

Al referirse a los símbolos patrios y la trascendencia que estos pueden tener en el proceso de la construcción de la identidad costarricense, se debería tomar en cuenta la opinión de la ciudadanía en general, incluyendo la posición de los jóvenes, quienes pasarán 
a ser los futuros líderes del país, como menciona Krauskopf (1998), quien se refiere a ellos como actores estratégicos del desarrollo de su futuro; sin embargo, por los juicios de valor que se generan a partir de la visión adultista y adultocéntrica, esta unificación intergeneracional no se lleva a cabo al tomar decisiones básicas para el progreso del Estado.

Castrillo reconoce la importancia que tiene la participación adolescente en definir los límites que identifican al sujeto cultural de una nación, debido a que en esta etapa del desarrollo, el joven es consciente, en la medida de sus posibilidades e intereses, de las ideologías que lo determinan como miembro de una colectividad, así intenta compararlas, discutirlas y justificarlas, a la vez que se posiciona frente a los demás (1998, p.22).

En relación con esto, Badilla, Guimarães y Vargas (1995) señalan que en el currículo docente de este país se incluye la temática de la identidad nacional, pero que los educandos interiorizan una falsa idea de homogeneidad que oculta las diferencias regionales y étnicas, ya que los discursos académicos no coinciden con la realidad a la que se enfrentan.

\section{Método}

Esta investigación es cualitativa y exploratoria, comprendida por una revisión bibliográfica, la realización de un grupo focal y el análisis de los datos recolectados, cuya finalidad fue estudiar los conocimientos relacionados con la identidad del ser costarricense y el imaginario nacional, en un grupo de adolescentes.

Se desarrolló en el ambiente natural de los participantes. Las categorías no fueron manipuladas ni controladas por las personas a cargo del estudio; se extrajeron los significados de los participantes, por lo tanto, los datos se valoran desde la visión y la propia experiencia de cada joven, y no se reducen a valores numéricos. Se procuró investigar sobre pensamientos y comportamientos de los adolescentes, relacionados con el desarrollo de su identidad.

Es exploratoria porque el fin fue examinar un tema en el cual existe un vacío en cuanto a la relación del adolescente con el constructo identitario nacional y la descripción del ser costarricense actual; esto permitió la familiarización de ciertas nociones relativamente conocidas, con el proceso de construcción de la identidad de los adolescentes, y abrió la puerta a siguientes estudios más profundos en el tema. Se dividió en 5 etapas relacionadas. En la primera parte se seleccionó el tema de trabajo, así como la revisión bibliográfica y la definición de nociones específicas. La segunda obedeció a la escogencia y delimitación de 
los participantes, y elaboración del grupo focal como herramienta de recolección de información. La tercera correspondió a la aplicación del grupo focal, es decir, el trabajo de campo, donde se interactuó directamente con la población del estudio. La cuarta parte implicó el análisis de la información obtenida y de los resultados. La parte final fue la redacción del informe a partir de los aportes de los jóvenes durante el grupo focal, y la formulación de recomendaciones por parte del grupo guía.

Debido a la naturaleza de la investigación, los integrantes del grupo focal debían ser adolescentes. Una célula de jóvenes perteneciente al Centro Internacional de Avivamiento, templo cristiano protestante ubicado en San Diego de Tres Ríos, se convirtió en el grupo focal de la investigación.

En cuanto a los criterios de inclusión y exclusión, se estableció que se incluirían jóvenes que cumplieran con: ser adolescente, estar entre los 14 y 18 años de edad cumplida, pertenecer a la célula de jóvenes del Centro Internacional de Avivamiento, asistir el día del grupo focal y participar en las actividades programadas.

Los participantes fueron 13 hombres y 4 mujeres. Habitan en lugares como las cercanías de San Pedro de Montes de Oca, Tres Ríos y San Francisco de Dos Ríos, y pertenecen a la clase media.

El grupo de jóvenes fue seleccionado a conveniencia, tomando en cuenta los objetivos del estudio. Si bien pertenece a una célula religiosa, esto no fue tomado en cuenta a profundidad para efectos del análisis de la información, puesto que el tema de estudio es la identidad en la adolescencia y la relación con el imaginario nacional como ideología de la cultura dominante, en general, y no la influencia de la ideología religiosa en particular.

Cabe señalar que se trabajó en una sola sesión grupal dividida en: introducción y presentación del tema, presentación de material audiovisual, discusión de la temática relevante y recolección de información. Como parte de los audiovisuales, se utilizó como material generador o de apoyo, 3 videos: el Himno Nacional de Costa Rica; Soy tico, de Carlos Guzmán, y Welcome to paradise, del cantante Yaco, que remiten al segundo uso del término de Wallerstein, ya que distinguen los comportamientos de "lo que es Costa Rica", entre la "alta" cultura costarricense y la de un corte más popular.

Además, se recurrió a una serie de preguntas abiertas que generaran discusión dentro del grupo focal, como por ejemplo “¿Para usted qué significa ser costarricense?”, “¿Cuáles 
características y símbolos presentados en los videos considera usted que sí representan a los costarricenses? ¿Por qué?”, etc.

En el grupo focal se expuso tanto el constructo de sujeto cultural costarricense, como el imaginario nacional en que se basa tal noción. A la vez, se analizó la visión del adolescente en cuanto a esta construcción identitaria, para lo cual se consideraron aspectos como: el conocimiento del tema y las nociones relacionadas, la posición del adolescente ante la temática expuesta, a nivel discursivo; observación por parte de las mediadoras, ante las reacciones del adolescente en relación con la temática expuesta; las relaciones y diferencias entre la posición que expresa el adolescente ante el tema, y la reacción que manifiesta durante la actividad.

Por último, se aclara que la información obtenida en el grupo focal, mediante la aplicación de estrategias participativas, se analizó a la luz del marco teórico planteado.

\section{El adolescente frente al ser costarricense en el imaginario nacional}

El grupo focal participativo "Adolescencia e identidad en el imaginario nacional", se realizó el 5 de junio de 2013, a una célula de jóvenes perteneciente al Centro Internacional de Avivamiento, que se reúne en el Salón Comunal de Calle Siles, ubicado en San Pedro de Montes de Oca.

En este, se observó que hay una diferencia significativa entre hombres y mujeres con respecto a la asistencia, siendo que es mayor la participación de los varones.

Se podría suponer que esta diferencia proporcional, en un ambiente de respeto y tolerancia, no debería afectar al tomar la palabra para discutir los temas varios que se exponen en las reuniones y se presentaron el día del grupo focal; no obstante, las mujeres conversaron menos que los hombres: solo una de las jóvenes compartió sus opiniones, principalmente relacionadas con los videos. Esto se considera una limitante del estudio, que abre la cuestión de hacer investigaciones que contemplen la variable género.

Antes de la actividad, el grupo de adolescentes desconocía por completo cuáles videos que se utilizarían, por lo que el factor sorpresa-reacción se contempló en el análisis de los datos. De modo que las reacciones de los adolescentes al escuchar el Himno Nacional, fueron, en general, de hastío. Si bien algunos tararearon la letra con un tono de tedio, los adolescentes comentaron que ese video "los tenía cansados", o que no podían con "ese tipo de varas". No solo hicieron mofa de la cantidad de veces que lo han visto u oído en su vida 
cotidiana, sino que bromearon entre ellos acerca de que había que ponerse de pie y que "mejor lo cantaran", porque con la lluvia que caía ese día, no se podía escuchar bien el audio.

Con el video de Soy tico, se comportaron de la misma manera, e incluso el interés disminuyó notablemente, porque no les atrajo la música, como comentaron después, y porque no estaban familiarizados con la melodía. Una situación que facilitó el entorno de burla en cuanto al contenido de la canción, fue que el video estaba subtitulado, por lo que bromearon con el estribillo y la "solemnidad" del tono musical.

En cambio, con la canción de Yaco se mostraron más entusiasmados: no solo se acomodaron en sus asientos para ver mejor, sino que comentaron sobre "la calidad musical" de la canción. Algunos muchachos se sabían la letra y como el audio no era bueno, sugirieron, una vez más, que la cantaran entre ellos.

En general, no consideraron necesario repetir los videos, porque aseguraron que ya habían visto muchas veces el del Himno Nacional y Welcome to paradise, mientras que el de Soy tico había dejado claro su mensaje y se complementaba fácilmente con el primero.

En cuanto a las apreciaciones de los videos, este grupo de adolescentes afirmó que había muchos contrastantes. Argumentaron que, en los primeros 2 videos, se enfatizó en aspectos buenos de Costa Rica, y su intención era demostrar un orgullo de ciertos elementos como "todo lo lindo que es ser costarricense", en otras palabras: los mares, las montañas, las playas, los ríos, los pájaros, la guaria, la lluvia, la flora, la fauna y los valores de las personas.

Por otro lado, el video Welcome to paradise lo percibieron como la parte fea o "el otro lado" del país. El contraste se debió a que menciona prostíbulos, drogas, asaltos, la suciedad, etc., todo circunscrito a la realidad costarricense. Algunos cuestionaron que esa no era toda la realidad actual de Costa Rica, porque no rescataba nada positivo, y los elementos que indica Yaco (asaltos drogas y prostíbulos, etc.), no son exclusivos del país.

Independientemente del "lado malo del tico" o "el lado actual", como grupo adolescente, se identificó más con la realidad del último video, pues los primeros fueron percibidos como un pasado nostálgico de cómo era la nación costarricense, o "antes de que naciera uno", del cual solo algunas partes los apelaban como individuos. ¿Cuáles son los elementos que considera este grupo de adolescentes como propios de los costarricenses? ¿Cuáles no? O bien, ¿en qué circunstancias no lo son? ¿Qué los distingue de otras 
generaciones de "ticos"? ¿Cómo es el tico que los representa a ellos como adolescentes? Estas son algunas de las cuestiones que se analizan en este apartado.

\subsection{La cultura nacional de Costa Rica desde la perspectiva de los adolescentes}

A partir de los videos escogidos, se les preguntó a los adolescentes cuáles eran las características del costarricense o "tico", y si el contenido de los videos, las imágenes, símbolos y personas, podía aplicarse para crear estas definiciones y conformarlos a ellos como personas, por lo que la conversación se dirigió, inevitablemente, a las características culturales de Costa Rica: sus símbolos patrios, su idioma y algunas de sus prácticas sociales, de acuerdo con la percepción del grupo adolescente, temas que se abordarán en este apartado.

\subsubsection{Símbolos patrios, reminiscencia del sistema educativo}

Durante el desarrollo del grupo focal, los adolescentes enunciaron los símbolos nacionales con facilidad, y manifestaron tenerlos muy presentes, por su reforzamiento en el periodo escolar por el que atraviesan. Al respecto, es fundamental rescatar que Arias (2009) y Patricia Safa (1991), coinciden en que la educación institucionalizada es un espacio para la transmisión de los valores y de los contenidos culturales, que procura heredar el imaginario nacional.

Los muchachos del grupo focal reconocieron los emblemas de la nación como parte de la materia obligatoria y necesaria para aprobar los cursos del colegio, no porque se sientan identificados con ellos, ni porque consideren que los representan como costarricenses. De hecho, por la información recolectada en el grupo focal, se puede inferir que el valor cívico que se pretende transmitir a partir de los símbolos patrios, está en crisis, pues los jóvenes participantes no se sienten identificados con ellos, como un elemento propio de la identidad nacional.

En general, el grupo mostró un amplio dominio, como ya se mencionó. Ellos destacaron la bandera, la carreta, el escudo, el yigüirro, la marimba, el venado cola blanca, que agrupan entre las características del costarricense en general, mas afirmaron que no los representan a ellos como individuos. Esto podría interpretarse como un problema que 
adolecen los símbolos patrios, pues no están funcionando como marca de identidad nacional, al no presentarse dentro de la realidad que viven los jóvenes.

Esto quedó demostrado en el grupo focal, cuando hablaron acerca de los emblemas, discutían cuales conocían realmente y cuáles no, por ejemplo, el escudo y la bandera los han visto y tocado, en el colegio hay algunos, y en ocasiones, decoran las instalaciones con estos ejemplares para las fechas que así lo requieren. Por otra parte, mencionaron que al ver la bandera en la cotidianidad, no se sentían representados.

Los participantes consideran que esta identificación solo podría suceder si se encuentran fuera del país, afirmó uno de los muchachos que "donde hay un tico, fijo se reconoce y es pura vida", porque los símbolos patrios recuerdan "todo lo que es" Costa Rica. Sin embargo, por las condiciones socioeconómicas, la posibilidad de un viaje al extranjero es improbable, pues no se encuentra entre sus aspiraciones, que se inclinan más a "tener un buen trabajo, carro, casa y tal vez una familia". Paralelo a esto, mencionan que en espectáculos musicales u otras manifestaciones artísticas, dichos emblemas son utilizados en posiciones discursivas nacionalistas, para diferenciarse de otros grupos culturales. Varios muchachos piensan que en ninguna circunstancia la bandera de Costa Rica los representa, porque esta no es más que una simple bandera; mientras que la guaria morada, el venado y el árbol de Guanacaste no los conocen en persona, solo han visto algunas fotografías de vez en cuando, porque la materia lo exige; esto no permite ningún tipo de identificación, pues no participan en actividades que los pongan en contacto directo, afirma uno de los participantes: "en agricultura sembramos plantas comestibles, árboles de frutas y así, no guarias", y al venado cola blanca ni se refirieron con amplitud.

Asimismo, el yigüirro no lo diferencian bien de otros pajaritos cafés, lo que quiere decir que no se conmueven con su canto y la emotividad que debería generar como ave nacional. En cuanto a la marimba y la guitarra clásica o popular, si bien los chicos las identificaron como instrumentos típicos nacionales, no es música que suelen escuchar en su vida cotidiana en sus casas o con sus amigos; solo uno confesó que escuchaba música folclórica nacional, pero aclaró que no es por elección, sino porque vive con la abuela y a ella sí le gusta.

Según lo que estos adolescentes afirmaron, las canciones con marimbas son "muy ticas", solo que eso no necesariamente coincide con sus gustos. Asimismo, declararon que no son instrumentos representativos de la música que ellos disfrutan, por lo cual tampoco se 
identifican con estos ni sienten la motivación de aprender a tocarlos. Varios se refirieron a estos símbolos como características de las generaciones pasadas: "son como parte de la vida de mis abuelos y de mis papás, son algo viejos, y están muy lejos de lo que realmente me gusta".

Finalmente, cabe mencionar que la identificación cultural de esta población con respecto a los símbolos patrios, se concreta mediante el sujeto cultural propuesto por Cros (2003), puesto que se evidencia la sumisión ideológica de los adolescentes ante los discursos que aprenden dentro del aparato escolar. Sin embargo, sí manifestaron que desean que se produzcan cambios sociales que favorezcan su progreso y valorización ante la identidad nacional.

\subsubsection{La ficticia oposición cultural}

Como se explicó en el referente teórico, la cultura de un grupo existe en la medida en que se diferencia de otras, lo cual es una manifestación exclusiva de aspectos ideológicos que cohesionan a ese grupo, con el fin de volverlos funcionales para determinada meta "colectiva". En cuanto al tema, los adolescentes mencionaron que el costarricense sí podría distinguirse, como grupo social, de otras nacionalidades centroamericanas, por 2 aspectos.

En primer lugar, los costarricenses son definidos como "más fresas o más cool, y menos cholos". En segundo lugar, consideran que el español de los costarricenses es un aspecto que los separa de otros hispanohablantes, pues puede ser "muy mal hablado", pero tiene una realización "estándar" en comparación con otras, como las de México, República Dominicana, Nicaragua o Colombia, que tienen una entonación característica o eliminan el fonema "s" al final de palabra.

En ambas percepciones, Costa Rica es definida con ese carácter excepcional, que señala Jiménez, en contraposición con el resto de Centroamérica, dado que el discurso oficial propone que Costa Rica está cerca de naciones más prestigiosas. Por ejemplo, la percepción del español costarricense como estándar es un tanto ingenua, porque a los costarricenses les cuesta detectar el "cantadito" (o entonación) en su vida cotidiana.

Por consiguiente, la construcción del imaginario utiliza esto como un punto válido para separar el país de Centroamérica y acercarlo a otros de índole más prestigiosa, como España, y los jóvenes -en su subjetividad- reproducen la instancia del sujeto cultural 
costarricense, al estar inmersos en las prácticas sociales que indican qué es ser costarricense, es decir, los estereotipos de superioridad, de "la Suiza centroamericana".

Otra diferencia que consideraron clara entre los centroamericanos y Costa Rica, fue carecer de ejército nacional y de grandes conflictos armados internos, lo que asocian a la libertad de tránsito y de opinión. Lo anterior es un ejemplo de la permanencia de valores costarricenses instaurados entre 1914 y 1948, según los cuales Costa Rica tiene la posibilidad de convivir mediante el respeto a la opinión diferente, el voto y la democracia.

No obstante, esta situación queda opacada con el sentimiento actual de inseguridad nacional, promovido en los medios de comunicación y por la inoperancia del Gobierno. Para los adolescentes, el costarricense no es pacífico por naturaleza y unido a una "ley sumisa" (comparada a otros países islámicos y el castigo a los ladrones, por ejemplo), existen lugares perdidos, debido a índices de criminalidad y a una sociedad corrompida.

Asimismo, comentaron que les resultaba paradójico que el país más pacífico y sin ejército defendiera a los Estados Unidos de América, cuando esa nación discrimina racialmente a todos los latinos. Cuestionaron, a su vez, la hipocresía del Gobierno al declarar asueto nacional con la llegada del presidente de esa nación (3 y 4 de mayo de 2013), y que el expresidente que se vanagloria de promover la paz, sea ahora quien esté anuente a que se firme el tratado de libre comercio de armas con ese país.

\subsection{La praxis del imaginario nacional desde un grupo de adolescentes}

En los siguientes apartados se examinará la posición de los adolescentes en cuanto a cuestiones del imaginario nacional propiamente dicho.

\subsubsection{Una cortina de humo ante la diversidad cultural}

Con respecto a las premisas "En Costa Rica todos los habitantes se parecen físicamente entre sí" y "Somos blancos porque no tenemos indios", las cuales se presentaron en el grupo focal como material generador de opiniones, los adolescentes consideraron que en el país no todos los habitantes tienen una similitud física, y no compartieron la posición de que, en general, el costarricense sea blanco. Esta postura de los jóvenes evidencia un distanciamiento en relación con el imaginario de una Costa Rica racialmente homogénea, de personas blancas, ideado por los liberales. 
Los adolescentes que participaron en el grupo focal también señalaron que en el país hay una presencia innegable de grupos indígenas y se denominaron a sí mismos como "mestizos", aunque algunos reconocieron haber escuchado que en Costa Rica no hay aborígenes. Los jóvenes que manifestaron una opinión más crítica consideraron que sí hay grupos indígenas, pero relegados en sectores lejanos, y que al Gobierno no le interesa colaborar con ellos, a la vez que no parece preocupado por valorar dicha diversidad cultural.

Algunos muchachos indicaron que hay una evidente invisibilización de estas poblaciones, puesto que los costarricenses tenemos raíces indígenas; incluso, uno de ellos señaló que los procesos de conquista y de colonización fueron las causantes de esto. La afirmación de este joven parece significar una progresiva concienciación de que el proceso de mestizaje ha sido manipulado desde el discurso oficial, para situar las culturas indígenas en el pasado y constituirlas como distintas y ajenas a los costarricenses.

Este mismo joven indicó que tuvo lo oportunidad de visitar unas comunidades indígenas situadas en Talamanca, y que le sorprendió negativamente observar el grado de pobreza y abandono al que están sometidas esas personas. Pese a lo anterior, varios de los adolescentes, al mismo tiempo que reconocían sus raíces indígenas, se burlaban de uno de sus compañeros porque parecía "un indio".

Por otra parte, en el grupo focal también se mencionó la población afrodescendiente de Costa Rica. Uno de los adolescentes señaló que "los negros son criminales" y que la mayoría de costarricenses se intimida si ve a un negro. Debido a esa opinión, otro joven (quien mencionó que su abuelo era negro) lo denominó "facho", ante lo cual el adolescente trató de redimirse, aseverando que sí existían negros exitosos y cultos, porque él conocía a una profesora negra con esas características. Resulta evidente que, para este muchacho, características como la inteligencia y el éxito son ajenas a ese sector de la población, de ahí que considerara oportuno resaltar que sí es posible encontrar personas negras que sean cultas y exitosas.

En las palabras de este adolescente, quedó manifiesto el sujeto cultural referido por Cros (2003), ya que es a través del lenguaje como se evidencia la identificación del sujeto cultural con una colectividad y, por ende, la diferenciación con otras colectividades. El sujeto cultural demuestra sumisión ideológica, puesto que reproduce reglas y estereotipos de otras colectividades, por eso la mayoría de los adolescentes del grupo focal identificó a los negros y a Limón, únicamente con problemas sociales como la pobreza y la criminalización. Aunque 
intentaron mostrar lo contrario, los jóvenes manifestaron una preferencia por la colectividad blanca, que salió a relucir en su discurso y con las burlas hacia los compañeros que, según ellos, tenían características propias de los indios y de los negros.

Discursivamente, la provincia de Limón fue descrita por los muchachos como la que tiene los males en el país. Sin embargo, reconocieron que hay un abandono por parte del Gobierno hacia esta, y una desvalorización de la diversidad cultural, lo cual contribuye a que las personas se construyan e identifiquen a sí mismas, a partir de sus supuestas diferencias con otras colectividades.

Un aspecto interesante que arrojó el grupo focal es que los adolescentes reconocieron que los medios de comunicación y la publicidad recurren a blanquear a los negros y a asignarles tareas que remiten a la esclavitud. Los muchachos pusieron el ejemplo de varios anuncios de productos de limpieza, en los cuales se presenta a personas afrodescendientes vestidas con ropa blanca y siempre llevando a cabo labores domésticas, como lavar platos y limpiar pisos.

Esta pasividad, producto de la interacción entre ciudadanos, se pudo observar al interpretar el folclor costarricense. Si bien es cierto, los jóvenes determinaron que fenotípicamente los costarricenses no pueden clasificarse como blancos, no percibieron la clara oposición cultural entre el ciudadano del Valle Central, de Guanacaste y de otras zonas como Limón, presente en el discurso del labriego sencillo guanacasteco, del cual hablan el Himno Nacional o la canción "Soy tico".

Dicho discurso demuestra la exclusión que han sufrido históricamente en el país otros grupos sociales, como el indígena y el afrodescendiente, posiblemente porque la vinculación entre el trabajador sencillo del Valle Central y de Guanacaste, remite a una "pasividad nacional", mientras que el de Limón lo hace a las bananeras y, por tanto, a luchas sociales desarrolladas en los primeros años del siglo pasado.

Ante la pregunta de si consideraban curioso o extraño que el folclor nacional esté solamente asociado a Guanacaste, un joven cuestionó el hecho de que el sabanero es del folclor guanacasteco, provincia que inicialmente es "más nicaragüense". Asimismo, consideró contradictorio practicar costumbres nicaragüenses, aunque en el discurso son asimiladas como estrictamente costarricenses, tomando en cuenta que los nicaragüenses son uno de los grupos sociales más discriminados en el país. 
Para los adolescentes, el labriego sencillo no es una cobertura ideológica para mantener el control de la sociedad a partir de la interiorización de la idea de que el costarricense es pasivo, sino que es una forma de definir a los ticos, especialmente en el pasado. Así, este grupo reconoció que, actualmente, "no somos labriegos sencillos, pero muchos países sí creen que eso nos define"; es decir, en el ámbito internacional se percibe a Costa Rica como un lugar primitivo, por las comidas típicas y los bailes, los cuales por "más ticos" que se hayan considerado, ya no son representativos por el cambio generacional producido.

Los jóvenes tampoco analizaron críticamente el discurso nacional de "Todos los ticos somos iguales y sencillos", que se puede observar en los dos primeros videos, puesto que en ambos se hace una clara referencia a los trabajadores costarricenses: el campesino sabanero, el pescador, el tico con chonete, el vendedor de flores, el copero, etc. Los trabajos típicos del costarricense, de acuerdo con los 2 videos, se oponen a puestos como los que ocupan los diputados, ministros, entre otros, sobre todo en cuanto a la remuneración económica y la posición social. En ese sentido, hay una recepción pasiva por parte de los adolescentes de lo que es ser costarricense, pues no se cuestiona la marcada brecha a nivel económico y social que viven cada vez más ciudadanos costarricenses.

Desde que se inició el proyecto de establecer a Costa Rica como una nación, la idiosincrasia del tico ha sido usada como cobertura ideológica para aglutinar al costarricense en un margen de pasividad y democracia, con lo cual se ha intentado ocultar que, en diferentes épocas, la población ha reaccionado contra las decisiones de sus gobernantes.

La doble cara que ha representado a Costa Rica desde el siglo XIX, cuando empezó a reafirmarse su identidad como nación, en cuanto a la realidad racial, social, económica, política y ambiental, también ha falseado las bases identitarias de la sociedad, ya que al haber dejado por fuera de la cultura oficial a muchos otros grupos étnicos significativos para el país, estos se han ido extinguiendo, perdiéndose a la vez sus aportes medicinales, culturales, gastronómicos, entre otros.

\subsection{2 ¡Pura vida!, marca registrada}

De acuerdo con los adolescentes, este costarriqueñismo es una forma de identificar al tico cuando se encuentra en el extranjero y, de esta forma, es fácil diferenciarlo de otras 
nacionalidades, ya que además el tico tiene una manera de hablar muy particular, carisma y amabilidad fáciles de reconocer.

Para el grupo adolescente con el que se trabajó, la expresión "pura vida" tiene diversos significados. Ellos consideran que es una expresión exclusiva de los ticos y utilizada con frecuencia en la vida cotidiana. La expresión puede ser empleada para describir la personalidad de alguien como "buena nota", es decir, considerar a un individuo como buena persona y en quien se puede confiar.

Además, es una expresión usada para hacer saber que la persona se encuentra en un ambiente de fiesta donde se siente con gran comodidad, o bien, puede utilizarse para describir lugares hermosos: playas, montañas, entre otros.

Este concepto no solo representa lo lindo, "lo chiva", lo amigable, la personalidad, el ambiente de fiesta en el que se desenvuelve un individuo, sino que además representa una especie de ironía, de sarcasmo o indiferencia de las personas ante situaciones malas o difíciles que se viven en el país y que afectan a la población en general; por ejemplo, uno de los estudiantes mencionó la situación de "la platina" y los asaltos que ocurren con frecuencia en diferentes partes del país, y que las personas suelen decir "ah, qué pura vida". Se puede notar con la expresión anterior, el conformismo o indiferencia en los que ha caído el costarricense.

Para los adolescentes, el "pura vida" sí describe la forma de ser del tico en general, pero puede ser usado como arma de doble filo. El ejemplo que propusieron los muchachos del grupo focal, en relación con el uso del "pura vida" fue en un sentido como de resignación, cuando se presta dinero o un par de zapatos. Ellos afirmaron que estas cosas no se devuelven nunca más, sino que hay que "echarle tierra", en palabras de adolescentes, por lo cual ellos dicen: "pura vida, se lo presté y no me lo devolvió".

Por consiguiente, el término "pura vida" oculta una especie de criminalidad, ya que la persona comete un robo y no devuelve "lo prestado", puesto que considera que su amigo es buena gente como para crear el pensamiento de no devolver lo prestado o para llevarlo engañado con frases como "se lo pago mañana" o "se lo devuelvo mañana" y, en realidad, el dinero o el objeto nunca vuelve a llegar a las manos de su dueño original. Según los adolescentes, esto representa un cambio en el sistema de valores de la persona.

La expresión costarricense "pura vida" es utilizada en una situación de doble cara, o en 2 sentidos primordiales: por un lado, caracteriza a los ticos en general como buena gente, 
carismáticos, positivos, colaboradores, entre otros. También, puede ser usada para ocultar la realidad en la que se vive, el conformismo, lo perezosos, los problemas sociales que atañen al país u otros, razón por la que se considera ambivalente.

Igualmente, el "pura vida" remite a una actitud conformista común, que se puede apreciar en el fútbol. Según los adolescentes, Costa Rica se define como un país altamente interesado en el fútbol $y$, a pesar de que no cuenta con un equipo de calidad, los costarricenses siempre se entusiasman si va a un mundial. En otras palabras, hay un claro conformismo ante la representación de Costa Rica en cualquier mundial, pues cuando gana un partido "todo el mundo está feliz" solo porque se logró ir al mundial, y no existe la intención de llegar más allá (es decir, campeonizar).

Realmente, ellos dicen identificarse con el "pura vida" del costarricense "tuanis", colaborador, carismático, entre otros, no con el del costarricense conformista, atenido a los demás, o perezoso, que se ve en la actualidad. Efectivamente, mencionan que es necesario realizar un cambio para dejar atrás esa comodidad y confort en el que viven las personas, un cambio necesario, sin olvidarse de dónde se proviene. Por eso, manifestaron observar una diferencia en la sociedad actual, y utilizaron como ejemplo la protesta de las personas por la concesión que deseaba realizarse con la carretera a San Ramón.

Por lo expuesto, se puede decir que sí hay un quebranto en la identidad del ser costarricense. Para ellos, lo que se considera "cultura costarricense" ha perdido sentido, lo cual no es del todo bueno, pues "no se puede perder la identidad, de dónde venimos". Consideran que es contradictorio: si viene un extranjero, se le da de comer un casado, un gallo pinto, empanadas "ticas", chiverre, café, pero a la hora de salir con los amigos, esa no es la comida que consumen, ya que se dirigen a los lugares de comida rápida como Taco Bell, McDonald's, etc.; en otras palabras, contribuyen a "lo que causa" que se pierda la autenticidad del costarricense, aunque comer eso no los haga más o menos ticos.

\subsubsection{Cuando los hilos se rompen: algunos cambios generacionales}

Los adolescentes manifestaron que, actualmente, se han producido cambios generacionales importantes para la sociedad. Entre los casos expuestos, se mencionó el papel que desempeñan las mujeres, que se ha estado rompiendo con esquemas patriarcales que han afectado tanto a la sociedad. Según ellos, este es un cambio que beneficia, pues en épocas pasadas solo podían ejercer labores domésticas, relacionadas con el cuido de niños, 
la comida, atender al padre y a los hijos. Incluso se realizaban matrimonios arreglados, los cuales consistían en que el padre era quien le conseguía el novio a su hija, y ella no tenía derecho a opinar si se deseaba casar con él o no, simplemente tenía que aceptar los mandatos de su padre.

Las cuestiones descritas han venido cambiando. Las nuevas generaciones han estado evolucionando en sus actitudes y los adolescentes con los que se trabajó lo califican como beneficioso, puesto que la mujer ahora goza de derecho a estudiar y a ocupar puestos importantes en la sociedad, es decir, ha demostrado su importancia social. Ellos mantienen claro, en especial la única mujer que opinó, que se debe avanzar aún más, ya que en cuestiones como el salario las mujeres todavía son discriminadas.

Incluso, es primordial mencionar un cambio radical que notan los jóvenes al decir "en casa manda mamá y mi papá tiene que hacerle caso", pues en cuestiones como los permisos, el padre dice "vaya y le pregunta a su mamá", para ver si la autorización es cedida al adolescente.

La idea de que "el tico es machista" se concibe desde el punto de vista de los adolescentes, como algo anticuada. Expresan que se está dejando de lado, debido a la serie de cambios en la mentalidad, de los cuales se consideran parte.

De la misma manera, aludieron a la cuestión de la virginidad. Aunque recalcan que depende mucho de los valores de cada persona, fomentados más que todo en el seno familiar, este tema ha cambiado en gran medida, citaron los adolescentes, puesto que antes era un delito si la mujer no llegaba virgen al matrimonio, y eso era visto como símbolo de deshonra para ella y la familia. La situación ha cambiado bastante, pues los adolescentes consideran que las mujeres ya no esperan a que el hombre llegue y las corteje como antes, sino que ellas mismas van y realizan acciones de cortejo.

Para este grupo de adolescentes, ese cambio generacional es bueno, tal vez por la edad en la que se encuentran, como lo menciona Freud, citado por Rice, "en el periodo de la adolescencia se necesita un objeto sexual en el cual descargar las tensiones sexuales que se producen" (1994, p. 33), lo cual es una característica propia de la etapa adolescente, y es por eso que se experimentación con roles, en el ámbito sexual.

Otro cambio generacional mencionado por los muchachos fue que los niños asumen su sexualidad a una edad más temprana. Ellos se compararon con sus hermanos que están en la escuela y afirmaron haberse "apretado" (besado) como hasta los 12 o 13 años, 
mientras que desde una edad más temprana, escuchan a sus hermanos que hablan de que "me gusta tal chiquilla". Con este tema surgieron opiniones diversas, pues algunos de consideraron que este cambio generacional puede ser visto como una pérdida de valores, ya que antes los niños pensaban en jugar y en la sociedad actual, en cambio, se piensa en "ligar".

Otra percepción de cambio fue que "antes todos dejaban las puertas abiertas, hasta cuando no estaban en las casas, ahora ni los ladrones dejan abierto mientras sacan las varas". Debido a la inseguridad en la que se vive, los adolescentes consideran que en tiempos pasados las personas eran más honradas y no pasaban situaciones como las descritas; por eso, ahora se vive entre rejas, alambres de púas o con perros bravos, por la inseguridad que hay.

\subsubsection{Un acto infranqueable: la hora tica}

Los muchachos mencionaron elementos y características que conforman la cultura costarricense; uno de los componentes negativos que consideraron importante al definir al tico en abstracto y a ellos como adolescentes, es la no puntualidad, es decir, "la hora tica", cuya solución es citar a los ticos 30 o 45 minutos antes, para iniciar la actividad a tiempo. Este comportamiento lo consideran íntimamente relacionado con la cultura costarricense y ellos lo reproducen en sus propios compromisos sociales; así, uno afirmó: "Hasta uno lo aplica, cuando va a hacer una fiesta, dice media hora antes para que más o menos la gente llegue a tiempo o si lo invitan a algún lado uno trata de llegar tarde para no tener que esperar".

Si bien consideran que es un aspecto negativo que los representa, piensan que la puntualidad es un valor que depende mucho de la crianza de la persona, y de todos los participantes, solo uno dijo que era puntual: "A mí me va mal por ser puntual porque siempre llego media hora antes y me toca esperar un montón". En otras palabras, es un comportamiento propio del costarricense, pero algunos "salen mejor librados".

Para finalizar este análisis, se puede señalar que, a pesar de que forman parte del constructo ideológico de "nación" e "identidad nacional" de Costa Rica, en el grupo focal no se desarrollaron ampliamente algunos temas, lugares o prácticas sociales que estaban previstos, como las "direcciones a la tica", "la belleza de las ticas", el Museo Nacional, el 
Teatro Nacional, el Tribunal Supremo de Elecciones, la plaza de la cultura, las iglesias cantonales, etc.

Además, en el refrigerio posterior a la actividad, los jóvenes tomaron los papeles en los cuales se pusieron las premisas relacionadas con el imaginario nacional, con la finalidad de buscar cuál los definía más. Algunos incluso cuestionaron las frases y las rayaron. Otros las utilizaron para hacer mofa de los compañeros.

\section{Conclusiones}

Cualquier sociedad requiere establecer un proyecto país para el futuro, el cual contemple cuáles son los valores que se consideran fundamentales dentro de la identidad nacional, cuáles son las metas o valores que se desea transmitir y, por supuesto, los agentes de cambio que lo llevarán a cabo. En este contexto, resulta vital contemplar el grupo social de la adolescencia a la hora no solo de constituir en el futuro, sino de crear el punto de partida. Siguiendo tal principio, este trabajo valoró la visión de la cultura costarricense y el imaginario nacional de un grupo de adolescentes - perteneciente al Centro Internacional de Avivamiento-, circunscrita en un proceso de elaboración de la identidad personal.

Los adolescentes demostraron no estar exentos del contacto con lo que se considera "la cultura nacional", al sentirse hasta cierto punto identificados con el modelo costarricense y con lo que consideran elementos propios de ese grupo cultural ("Pura vida", "mae", "la hora tica", la comida, la paz, la libertad, etc.). Estas características los interpelan como un grupo específico, en contraposición a otros países de Centroamérica, y demuestran una sumisión ideológica en él, al reproducir estereotipos. Si bien no se identificaron con todos los símbolos nacionales, los reconocieron rápidamente, producto de la educación como práctica social, y por socialización.

Si bien desconocen a ciencia cierta qué sería lo que los define como costarricenses, para ellos es necesario redefinir los símbolos nacionales, el imaginario nacional y reescribir el Himno, ya que existe un cambio en el estilo de vida y su contenido está obsoleto: el labriego sencillo y la carreta pertenecen a un pasado nostálgico e irrecuperable, al contraponerlo con sus experiencias de vida actuales y las de sus padres.

Estos adolescentes mostraron conciencia de que en Costa Rica no existen políticas gubernamentales que le den una visibilización real y le otorguen a grupos étnicos significativos para el país, el lugar que merecen en la cultura nacional. Sin embargo, a través 
de sus palabras y actitudes, evidenciaron una predilección e identificación con la colectividad blanca, pues construyeron al indígena y al negro desde estereotipos y diferencias. Así, este grupo de adolescentes ha mostrado cómo la discriminación se reproduce en cada generación.

Pese a que, hasta cierto grado, se ha producido un distanciamiento de los adolescentes con respecto al imaginario de una Costa Rica racialmente homogénea y blanca -al aseverar que no todos los costarricenses son blancos ni parecidos físicamente-, es mediante sus prácticas discursivas que queda de manifiesto el sujeto cultural que han construido y que evidencia la continuación de estereotipos que dicen negar. Este hecho se puede percibir en los muchachos por la chota y el lenguaje para describir a los negros e indígenas, creados históricamente como una otredad lejana a la identidad costarricense.

Resulta evidente que la invisibilización de la que la población afrodescendiente e indígena fue objeto en el discurso identitario costarricense, ha dejado una huella que todavía es posible percibir a nivel discursivo en la juventud del país.

En definitiva, los adolescentes consideraron al "labriego sencillo" como un constructo identitario del pasado, pero no se percataron del trasfondo ideológico que esta caracterización ha tenido en la mentalidad del costarricense, pues lo ha llevado a pensarse a sí mismo como "pasivo", "sencillo", "pacífico" y "pura vida", lo cual podría explicar el adormecimiento y conformismo que los mismos muchachos reconocieron en su modo de ser.

Desde su perspectiva, la identidad nacional y los valores utilizados para describir al costarricense, están en crisis, pues la cultura ahora está más globalizada y el Estado no hace nada al respecto. Esto convive con una visión nacionalista -un "amor a las raíces"-, pues consideran que se deben rescatar y preservar ciertos valores costarricenses, como la comida típica, a pesar de que, generacionalmente, esto ya no los representa.

Eso es comprensible, ya que elaborar un imaginario nacional o un listado de características del costarricense, no es nada sencillo, sin mencionar que ellos como individuos todavía están en proceso de construcción de su propia identidad, y en búsqueda de un sentido de pertenencia. Además, al ampliar el tema a un contexto nacional, el tico, al no saber de dónde viene, ni dónde está, tampoco puede visualizar un futuro mejor con mayores oportunidades en todos los sentidos posibles, las cuales no siempre se relacionan con el nivel de progreso adquirido. 
Este grupo de adolescentes considera que muchos elementos se han perdido y ellos han colaborado con eso, como lo es la comida típica, aunque están conscientes de que tomar café y comer tortilla no los define como costarricenses. Otros cambios generacionales son descritos de manera positiva, como la valorización de la mujer en la sociedad y las luchas sociales, y otros de manera negativa, como la temprana asimilación de la sexualidad por parte de los niños y la inseguridad que perciben básicamente como una pérdida de valores.

Asimismo, creen que es necesario mantener una distancia con valores costarricenses como el machismo, el conformismo y la pasividad, pues consideran que no es beneficioso ni para la sociedad, ni para ellos como personas. La hipocresía, el conformismo y la mediocridad, son características que identifican al costarricense, pero que no deben interpretar ellos como valores propios.

En ese sentido, piensan que no se deben asumir características negativas por más costarricenses que sean, visión que resulta vital al definir una identidad. De esto, se puede concluir que los adolescentes como sujetos, aunque el sujeto cultural los obligue a simularlo, se apropian en mayor o en menor medida de la cultura de la sociedad a la que pertenecen.

Al llevar a cabo este grupo focal con adolescentes, principalmente por la temática que se abordó y por el grupo etario con el que se trabajó, es fácil darse cuenta de las razones por las cuales Jiménez (2008) considera que, a partir de las 2 décadas finales del siglo XX hasta estos días, solo se poseen "algunas intuiciones inconexas" acerca del proceso de invención de la nación y de la nacionalidad costarricense.

El actual periodo histórico de construcción nacional costarricense, especialmente desde la perspectiva adolescente, se debe pensar tomando en cuenta factores como el peso que los medios de comunicación tienen en la mentalidad de los ciudadanos; la irrupción de Internet y de las redes sociales en la vida cotidiana; la creciente inmigración hacia el país de nicaragüenses, colombianos y de otras nacionalidades, así como el cuestionamiento que se está llevando a cabo del sistema político, sus protagonistas y sus acciones. Estos factores, como se pudo comprobar en los resultados del grupo focal, indudablemente han repercutido y seguirán haciéndolo en la percepción que los costarricenses, pero sobre todo los adolescentes, tienen sobre sí mismos y los demás.

Por último, sería conveniente desarrollar este grupo focal con otras poblaciones de adolescentes, no solo para recabar datos que ayuden a vislumbrar el imaginario actual 
costarricense, sino porque mediante el cuestionamiento de este y de la cultura nacional, el adolescente puede reflexionar sobre su identidad y cómo él, como sujeto, puede distanciarse de la regulación del sujeto cultural costarricense.

\section{Referencias}

Arias, Leonel. (2009). La identidad nacional en tiempos de globalización. Revista electrónica Educare; XIII, 7-16.

Badilla, Patricia, Guimaráes, Sonia y Vargas, Rosa. (1995). Educación rescata nuestra identidad cultural. Revista Herencia, 7(1) p. 90-101.

Castrillo, Jorge, Fernández, Agustín y Ordoñez, María Alicia. (1998). La adolescencia desarrollo psicosocial e implicaciones educativas. San Salvador: Editorial Piedra Santa.

Cros, Edmond. (2003). El sujeto cultural: sociocrítica y psicoanálisis. Colombia: Fondo Editorial Universidad EAFIT.

Cubero, Carmen. (1995). Características psicológicas y tareas básicas del adolescente. Conferencia inédita.

D’Antoni, Maurizia y Pacheco, Xenia. (2004). ¿Por qué? Jóvenes ante el desorden mundial. Universidad Nacional.

Escobar, Francisco. (1995). Juventud y cambio social. Apuntes desde una perspectiva sociológica. Costa Rica: Ministerio de Cultura, Juventud y Deportes.

Grosser, Kattya. (2003) Adolescentes y adultos ¿Es posible una interacción sin juzgar ni castigar? ¿Qué hay detrás del llamado conflicto generacional? Revista Actualidades en Educación, 3(1). Universidad de Costa Rica. Recuperado de http://revista.inie.ucr.ac.cr/buscararticulos/controlador/Article/accion/show/articulo/adolescentes-y-adultos-es-posibleuna-interaccion-sin-juzgar-ni-castigar-que-hay-detras-del-llamado-conflictogeneracional.html

Guzmán, Carlos y Grupo Gaviota. (7 de noviembre, 2007). Soy tico. Recuperado de http://www.youtube.com/watch?v=k b461aac3w

Jiménez, Alexander. (2008). El imposible país de los filósofos. San José: Editorial de la Universidad de Costa Rica.

Krauskopf, Dina. (1998). Participación social y desarrollo en la adolescencia. Recuperado de www.binasss.sa.cr/revistas/ays/2n1/art8.htm-71k

Quesada, Álvaro. (2002). Uno y los otros: identidad y literatura en Costa Rica 1890-1940. San José: Editorial de la Universidad de Costa Rica. 
Rice, Philip. (1994). Adolescentes desde el contexto teórico. En Philip Rice, José Antonio Carranza, Adolescencia, desarrollo, relaciones y cultura (pp. 31-53). Editorial PrenticeHall.

Safa, Patricia. (1991). ¿Por qué enviamos nuestros hijos a la escuela? México D.F: Editorial Grijalbo S.A.

Himno Nacional de Costa Rica cantado. (31 de octubre, 2010). Recuperado de http://www.youtube.com/watch?v=Rn5noyZNGhs

The University of Chicago Medicine. (s.f.). El desarrollo cognitivo. Recuperado de: http://www.uchicagokidshospital.org/online-library/content=S04694

Wallerstein, Immanuel. (2004) Capitalismo histórico y movimientos antisistémicos. Madrid: Ediciones Akal.

Yaco. (19 de octubre, 2011). Welcome to Paradise. Recuperado de http://www.youtube.com/watch?v=rquFXtiYbbU 